without measuring the acid, and was known to be more strongly impregnated at one time than another.

In none of the cases was there an excessively high temperature, or a frequent pulse observed, which could possibly be considered as due to carbolic poisoning.

In eighteen cases the clamp was used, and in thirty-two the ligature ; in one of the latter a drainage-tube was also inserted. In the patient who died the pedicle was tied. One patient was in the fourth month of pregnancy, and was afterwards confined at term of a living daughter. I am, Sir, yours truly,

Birmingham, Dec. 18th, 1880. THOMAS SAVAgE.

P.S.-Since writing the above, the patient upon whom I last operated died four days ago, so that my statistics should be stated as 2 deaths in 50 operations, and not 1 in 50, as stated above. The death was due to one of those unforeseen and, as far as can be told at present, unpreventable causes-viz., tetanus, which will always be liable to step in and raise the mortality of ovariotomy, apart from the question of antiseptics or nonantiseptics. The patient was perfectly well up to the ninth day; wound healed without pus; sutures removed, and looking forward to leaving the hospital. She first complained of a little "cold" from a window draught, and from that symptoms of tetanus developed, which terminated her life in twenty-four hours. At the post-mortem made by Dr. Saundby there was no appreciable cause for death. The abdomen was quite healthy; a piece of small intestine was adherent to the stump, and there was not a trace of serum or pus to be seen in the pelvis. I am now sorry that I did not wait a little longer before sending the record of my last fifty cases; but I was anxious to make the contribution as soon as possible after the Medico-Chirurgical Society's discussion.

December 27th, 1880.

\section{NEW FORM OF GAG.}

To the Editor of THE LANCET.

SIR,-I would venture to recommend a somewhat novel form of gag, which will be found useful in operations for the removal of tonsils, and in some cases of staphyloraphy. The instrument is essentially Mr. Rose's double-ended modi-

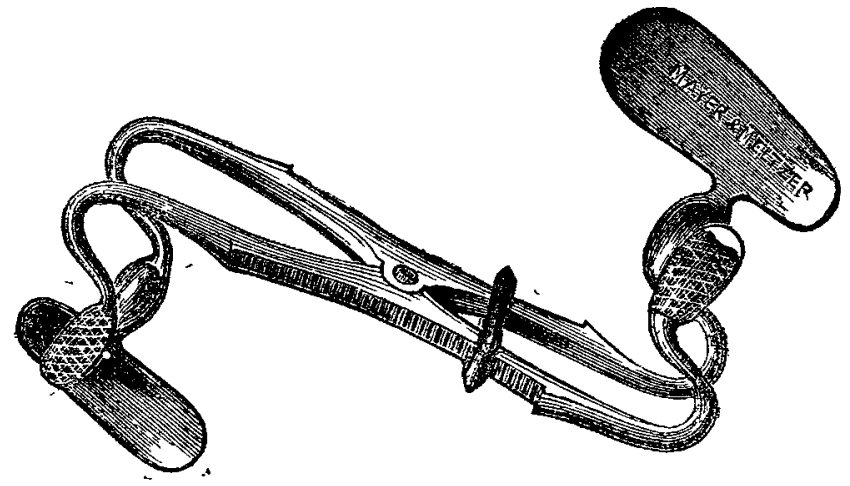

fication of Mr. Coleman's gag, to which Messrs. Mayer and Meltzer have adapted an ingenions sliding-ring-catch, to keep it open. To this a tongue-plate is now added, so that the gag answers almost all the purposes of the more expensive instrument usually employed in operations on the palate. The accompanying illustration will probably save the necessity of a further description.

Stratford-place, Dec. 31st, 1880.

I am, Sir, yours obediently, Thomas SuITH.

\section{ON CHIAN TURPENTINE AND PROF. CLAY.} To the Editor of THE LANCET.

SIR,-I deeply regret that the remarks with which I prefaced the report of my cases, and which were intended to convince Prof. Clay of the readiness with which we gave the Chian turpentine a fair trial at the Middlesex Hospital, and the satisfaction with which we should have welcomed any measure of success from it, have failed in their object, and have apparently left room for him to suppose we have "a prejudice against the Chian turpentine treatment not justified by the cases recorded." I would also mention for his information that the resolution of the Medical Committee was passed not owing to the results of my experience alone, but to those of my colleagues as well.

Although Prof. Clay says in his letter of last week, "I have never yet affirmed Chian turpentine to be a positive cure for cancer," I think it very pardonable if he has been misunderstood on this point; for he has made statements which to the ordinary mind distinctly imply the contrary. For instance, in his first communication (THE LANCET, March 27th, 1880) he has written, "Judging by my experi. ence it is no figurative expression to say that it acts as a direct poison upon the growth, probably causing its ultimate death ..... In the early stages of cancer it may be affirmed that an undoubted cure may take place speedily,......and expe. rience justifies the expectation that under such circumstances a recurrence of the disease will not follow." He has recorded a case (Case 2) in which the os and cervix uteri "were enlarged from carcinoma to the size of a hen's egg. The os was dilated and the cavity of the cervix was filled with epithelial growth which bled freely"; and the result of treatment is described thus: "The case was a most remarkable one. The turpentine acted upon the growth with great vigour, literally melting it away in the brief period of four or five weeks," and it is added, "She had continued quite well." In his second article (THE LANCET, October 2nd, 1880) Professor Clay says, that the cases previously reported by him "are unique of their kind, for, as far as I know, they are the only instances on record of cancer being cured solely by the administration of an internal remedy. I feel justified, there fore, in stating that uterine cancer at least may be removed by the use of Chian turpentine." And further on he writes: "It is possible, therefore, to formulate a line of treatment which shall be successful in cancers of the uterus." In short, his writings teem with phrases which imply, when they do not absolutely state, the curative agency of the treatment he adrocates.

Nor do his published statements permit him to object, con. sistently, to my cases on the ground of their severity, and to say, "It was never contemplated by me that the remedy should be used in the treatment of cases verging on death, as five of the uterine cases reported by Mr. Morris evidently were." On referring to Prof. Clay's first case we find him stating, "The patient evidently had not a long time to live. The uterus was so extensively destroyed by the cancerous ulceration that its cavity readily admitted three fingers." The case was so desperate that it seemed to Prof. Clay justifiable to try the Chian turpentine "even if the remedy should produce unfavourable symptoms." Yeton the twelfth day, as he informs us, "the os was quite contracted and would now scarcely admit the finger ; " in the twelfth week the parts were cicatrising, the patient's health good, and she could walk a mile or two easily. In his second paper Prof. Clay says: "It is advisable not to be too precipitate in rejecting a case of uterine cancer on the ground of its being too far advanced for treatment," and he then goes on to state how that the patient, who is said to have been told at the Middlesex Hospital "that her case was incurable, and that she had not long to live," was so much improved in nine weeks that she was about to return to London, "with every prospect of soon being cured." In the face of these statements, it is perfectly amazing that Prof. Clay should object to any case short of one actually moribund.

But it is a distinct, although I am willing to think an unintentional, misrepresentation of my cases for Professor Clay to say respecting them : "Nor did I ever suggest or imagine that Chian turpentine would build up a new nterus, or repair a cancerous fistula of the intestines,' or patch up a great cavity into the bladder, or restore a large recto-vaginal fistula with the fundus of the uterus extensively destroyed. Yet several of the cases described by $\mathbf{M r}$. Morris were of this character." These were the conditions brought about by the ravages of the disease during the administration of Chian turpentine over periods varying in the several cases from seven weeks to nearly seven months, and found at the post-mortem examinations; not the conditions at the time the treatment was commenced. Moreaver, some of the patients who have been taking the medicine for months are still going about, although getting gradually worse.

Indeed, no one who will take the trouble to read my cases, as well as Professor Clay's, can arrive at any other conclusion than that even in the worst of my cases the cancer was in a less advanced stage when the turpentine was commenced than in those cases of Professor Clay in which b obtained such brilliant and merciful results. 
Ir. sir. it were not for the encroachment on your space, $\mathbf{I}$ would place brief abstracts of Professor Clay's cases, and a corresponding number of the most severe of my own, side by side, for immediate comparison; and it is with reluctance that I forego doing so.

I will, however, conclude by saying that if the twelve cases which I have published are not thought by the profession (for I fear I cannot hope to satisfy Professor Clay) to be sufficient, or sufficiently conclusive to show the utter uselessness of Chian turpentine in the treatment of cancer, I am prepared with other facts and cases in support of my opinion that "there is not a single symptom over which the drug seems to exercise even frequently, not to say constantly, an influence."

I remain, Sir, your obedient servant,

IInnsfield-street, Dec. 13th, 1880. HENRY MORRIS.

\section{S C O T L A N D.}

(From our own Correspondents.)

\section{EDINBURGH.}

THE past year has been rendered eventful in the Edinburgh Medical School by the managers of the Royal Infirmary suddenly abolishing the tutorial class of gynæcologrical instruction attached to the University wards. It is stated that the managers have under consideration the whole subject of tutorial classes, more especially those conducted by gentlemen who are not on the acting staff of the institution. The summary measure already adopted seems unsatisfactory to the mass of the teachers, and is decidedly unpopular with the students, who are well aware of the importance of such practical work, and who highly appreciate the benefits there obtained. In his inaugural address at the beginning of the session the President of the Royal Medical Society drew attention to the value of practical classes and ward work, and pointed out that all would gain by an extension and improvement in the tutorial system. One of the surgeons has been giving ether a trial since the beginning of the session; an inhaler and anhydrous ether are used just as employed by Dr. Thomas Keith.

On New Year's night the usual melancholy results of this "much too festive season" were apparent in the continuous stream of accidents that kept pouring into the hospital waiting-room. Among these were a compound fracture of the patella, a railway smash of the arm, necessitating amputa tion of the arm at the shoulder-joint, besides many simple fractures and cut heads. Most of this was due, more or less, to drink. A few cases of alcohol poisoning are reported from Glasgow.

At the annual meeting of the Scottish Society for the Prevention of Cruelty to Animals, held on Dee. 28th in Edinburgh, the Secretary stated that the cases reported by the officers of the Society had somewhat increased, the number for the past year being 31l. The Chairman, Mr. Josiah Livingston, referring to the practice of vivisection, said they could do nothing to prevent this system of cruelty. Physicians and surgeons were licensed for the purpose of giving demonstrations, and they had no means of bringing those persons under the operation of the law. Another gentleman stated his belief that vivisection was certainly the most horrid species of cruelty to animals that could possibly exist. Councillor Sloan referred to several important discoveries in science and medicine made through the practice of virisection, and said that the saving of a single man's life was worth more than all the cats and dogs in the town. Several ladies and gentlemen rose to their feet, and denounced Mr. Sloan's sentiments in an excited manner. When quiet had been restored, Mr. Sloan asked what a single human life was in comparison with all the cats and dogs nursed and pampered in the New Town? He was not there as an apologist for vivisection? But were researches in science and medicine to be baulked by mere sentiment? On its being stated that the question of vivisection was not before the meeting, the subject afterwards dropped.

\section{GLASGOW.}

THE medical schools of Glasgow were never in a more flourishing condition than at present. The total number of students attending the University this year is 2281, against 2220 last year, an increase of 3 per cent. In Medicine alone
557 students have entered, against 539 last year; so that, judged merely by numbers, the University has maintained and improved its position. The schools at Anderson's College and at the Royal Infirmary appear to share this prosperity. A feeling has lately been growing up, however, that it would be to the interest of both these institutions that their rivalry should cease and that their medical schools should be amalgamated; and the arguments in favour of this view are strong. This proposal has not yet taken any definite shape, and it is questionable if it can be satisfactorily carried out, considering that many of those more immediately interested would be sure to give it their hearty opposition. A fourth medical school has recently been started in Glasgow, in rooms situated at the gate of the University. Its lecturing staff consists of Dr. W. L. Reid, Mr. D. A. Knox, and Mr. D. C. M'Vail, who give instruction in obstetrics, surgery, and medicine respectively. It is still "the day of small things" with this school, but who knows what it may grow to?

Much interest is being shown in Glasgow in the move. ment for the erection of a hospital on the south side of the river. This scheme was, very properly, first taken up by the Glasgow Southern Medical Society two years ago, and from the amount of support which was at that time promised to it it is tolerably certain that it would long ago have been brought to a successful issue but for the unparalleled de. pression of trade which existed at that time, and which, perhaps, affected Glasgow more deeply than any other city in the kingdom. A few months ago the Hospital Committee of the above-named Society again began active operations, and as a result of their efforts a large provisional committee of employers of labour and other influential gentlemen has been formed, with the view of carrying on the work. The arguments adduced in the Committee's circular are such as to leave no doubt that the accommodation they ask is most urgently needed. It is scarcely credible that a district teeming with workshops and factories, having a population of over 200,000 people, largely of the working and indigent class, should be with. out a single hospital bed or a general public dispensary; or that patients coming from the southern suburbs and from the country towns beyond, suffering from severe accident or serious acute disease, should have to be jolted for many miles on the way to hospital, an experience which doubtless frequently makes all the difference between life and death to the sufferer. Large as the existing hospitals on the north side of the river are, they often fail, even in summer, to afford the accommodation required, and in winter their doors are besieged daily by a crowd of applicants, sometimes two hundred in number, waiting their turn for admission. The* wealthy men of Glasgow are always ready to give freely for charitable and benevolent objects; they have a reputation to sustain in this matter, and it is indeed seldom that they have such a strong case presented to them. They will belie the estimate formed of them if they do not soon raise the comparatively small sum, $£ 20,000$, required to float this scheme.

The Glasgow sewage question is still unsolved. It has engaged the attention of successive town councils for a number of years, but no satisfactory conclusion has yet been come to. Meantime, the state of the river Clyde, the harbour, and the shores of the upper part of the Firth, is becoming daily worse. A short time ago the endemic prevalence of "influenza" (which in many respects resembled typhoid fever) in Helensburgh and the Gareloch district was attributed, and apparently with justice, to the deep deposit of decomposing mud and sewage brought down from Glasgow, and lefton the adjacent shores. The latest suggestion as to the disposal of the city sewage comes from Dr. W. Wallace. In a paper read by him before the Philosophical Society of Glasgow he recommends the precipitation process, and considers lime the least precipitating agent obtainable at a reasonable expense. Alumina is better, but is much more costly. About forty tons of lime would be needed daily for the treatment of forty to seventy million tons of liquid sewage, at a cost of rather less than $£ 9000$ per annum. 'The effluent from this precipitating process, though not perfectly clear and pure, would not, under any circumstances, give rise to a nuisance. Dr. Wallace also announced that a new precipitation process, cheaper to work and giving even better results, would soon be made public.

In the recently-issued annual report of the Glasgow Western Infirmary it is announced that during the past year 12,782 out-door and 2052 in-door patients have been treated, 